\title{
Communication Through Digital Engineering Processes In AN Aircraft Program
}

\author{
Bhanumathi K S ${ }^{1}$ and B Haridas ${ }^{2}$ \\ National Civil Aircraft Development, CSIR-National Aerospace Laboratories \\ Old Airport Road, Kodihalli, Bangalore 560017, India \\ ${ }^{1}$ bhanumathi@nal.res.in \\ ${ }^{2}$ harienal.res.in
}

\begin{abstract}
An aircraft is a complex, inherently multidisciplinary product that requires real time global collaboration for Design, Manufacture and Service. Digital engineering processes play an intelligent role in product and process design from concept to retirement, which is around 70 years. The entire engineering data is hierarchically structured and traced throughout the lifecycle under strict Configuration Control (CC). This requires an accurate, easily communicable Digital Mock-Up(DMU)as a Virtual 3D-static and dynamic platform for, real-time concurrent engineering through wide collaboration, a sample of which is presented herein. Holistically, this requires a networked Product Lifecycle Management (PLM) system as an Integrated Digital Environment (IDE) for engineering (primary and continuous improvement) for life cycle of the aircraft. The latest feature in PLM is the use of Model Based Engineering.
\end{abstract}

\section{KEYWORDS}

PLM, IDE, CC, DMU, collaborative design

\section{INTRODUCTION}

Since 1991, the year of launch of open market based economic reform, the Indian economy has triggered an air traffic growth of about 7 to $8 \%$ per year both in PAX and cargo, international growth rate of about 3 to $4 \%$ per year. This has led to forecast of civil transport aircraft requirements of 100 to 200 per year to be added covering Long haul, Regional's, general aviation categories[1]. Also the industry today has aircraft and engines whose development involves the use of dynamic maintenance packaging, diagnostics, prognostics, autonomic logistics and total lifecycle asset management through advanced information technologies [2]. The situation provides opportunity for design, development, manufacture and servicing of aircraft, systems, and even engines. This opportunity beckons the engineering industry to create an engineering eco system, comprising design, manufacturing engineering, tool engineering, production facilities, servicing engineering facilities. The first requirement of such eco System is an intelligent IT infrastructure using Integrated Digital Environment (IDE). Figure 1 shows the global engineering collaboration using IDE.

\subsection{Goals of IDE}

Standards for data, IT infrastructure for life cycle product engineering

DOI : 10.5121/ijait.2013.3403 
Timely and accurate configuration control of the product

Digital Mock-Up based life-cycle engineering

Model-Based Engineering (Structure \& Systems)

Workflow-enabled processes in virtual/digital environment though PLM tool

Community Collaboration through inter-operable systems

In-place security processes and procedures

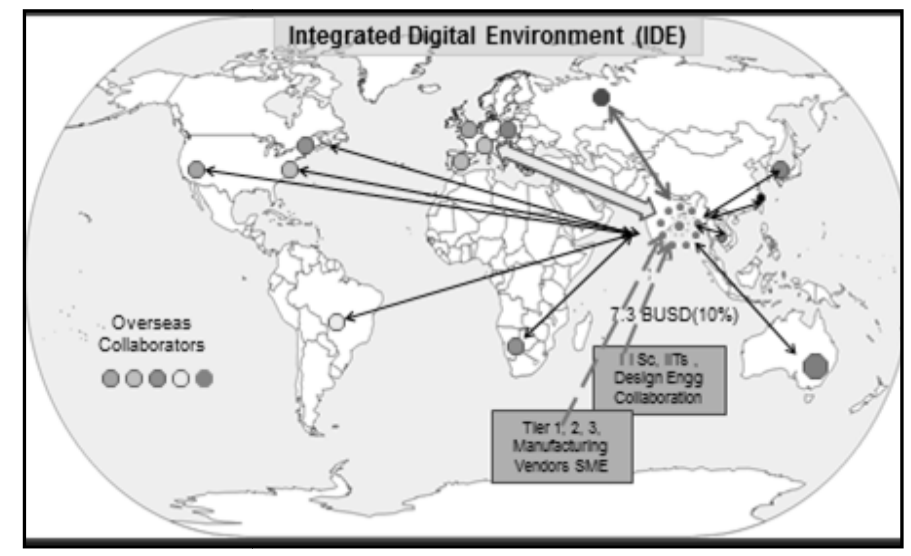

Figure 1.Global engineering collaboration scenario

\section{Characteristics of Digital Engineering Processes}

The practice of loft and physical mock-up based aircraft design is to be replaced by the more efficient Digital Mock-up (DMU) based engineering, where all design engineers will add their portion of the product design on a visual DMU in Virtual reality, under Configuration Control. It is necessary to build a digital engineering processes that enable innovation, reduce time to market and re-engineering through concurrency and collaborative actions between myriad R \& D and engineering agencies, instead of the past successive actions in vertically integrated set ups, which were resulting in excessive re-engineering, effort and cost. In the aircraft industry, lack of effective communication between the functions of design, manufacturing and assembly causes delays and setbacks whereby production capabilities are unable to realize design intent in highcomplexity product models [3].It provides a safe-net against challenges arising from continuous innovations, global collaborations and at the same time, making product and process data accessible to everyone [4]. Collaborative models reduce delays and eliminate errors. In such an environment, legacy paper-based and manual data exchange/synchronization processes are no longer required [5].This intelligent communication is provided by an open PLM business/engineering process that features a proven Service Oriented Architecture (SOA). SOA introduced in an attempt to allow for breakdown and re-assembly of business models and processes into services, built on layers of open standards and is capable of handling changes through each of the stages and across the life span of the elements. It is a well-defined, selfcontained 'service' function that does not depend on the context or state of other services. It plays a crucial role in dealing with the challenge of a heterogeneous environment containing integrated systems, making sure that work flows with flexibility and robustness. Promotes re-use of components, reduces development and deployment costs[6].Online /Real Time engineering collaboration, through Web in different Modes (immersed or synchronous or asynchronous) AND /OR Online/Real Time engineering collaboration, through Cloud Computing using Software as 
International Journal of Advanced Information Technology (IJAIT) Vol. 3, No. 4, August 2013

a Service (SaaS), Platform as a Service (PaaS) and Infrastructure as a Service (IaaS).The engineering communication process is an open architecture and high Computer Aided Design $(\mathrm{CAD}) /$ Computer Aided Engineering (CAE)/Computer Integrated Manufacturing (CIM) interoperability and covers the engineering processes in the following engineering domains from concept to retirement in geographically separated centres in an IDE for collaborative concurrent design.

$>\quad$ Product Design (Functions, Materials, Systems Geometrics, Design For Manufacturing and Assembly (DFMA),Design For Reliability and maintenance using CAD/CAE/ MBE, DMU, Simulation, Testing and Validation

$>\quad$ Process design (Digital manufacturing/assembly Simulation, Tool Design and virtual dynamic validation,

$>\quad$ System engineering on basis of Model Based System engineering

$>\quad$ Flight test engineering and execution process

$>\quad$ Airworthiness engineering processes

$>\quad$ Manufacturing execution system

> Maintenance Repair Overall(MRO)/Service Data Management (SDM)system

$>\quad$ Computerized Maintenance Management System (CAMMS)

$>\quad$ Life Cycle maintenance upgrade engineering support system

$>\quad$ Seamless Interfacing with Enterprise Resource Planning (ERP)/Supply Chain Management (SCM)

All of these work under governance of the PLM backbone and tail no based Configuration control.

\section{Digital Engineering Processes}

Aircraft industry has recognized that to stem the competition and survive in business [7], it is necessary to speedily absorb results of continuing R\& D, into the product or service. This requires an IDE based PLM. An IDE provides hardware, software, visualization platform to all the engineering players in an aircraft program throughout its life, to carry out their innovation functions through CAD, CAE, CIM, CAM software and have the execution carried out by ERP systems duly interfaced. In creating such a system CAx tools (Computer Aided, where $\mathrm{x}$ stay for Design, Styling, Manufacturing, Engineering, Process Planning, etc.), PLM tools, and smart technologies like cloud computing have revolutionized modelling techniques, virtual prototyping, digital mock up and created intelligent factory networks that encourage effective collaboration [8],[9]. For high interoperability, a light weight CAD neutral format providing high accuracy visualization and manipulation platform called DMU to all engineers.. All Engineers can see assemblies as they are evolving with the components designed into the DMU by different engineers globally. Assembly analysis tests are carried out for some components intersecting on assembly (Design error), kinematic simulation of the functioning of the product and testing of dynamic stresses and finite element analysis. In short, all the stages of the life cycle are simulated in VR and aircraft is preassembled on computer [10]. The fields covered for enveloping by an IDE /PLM are given in Figure 2 [11]. 


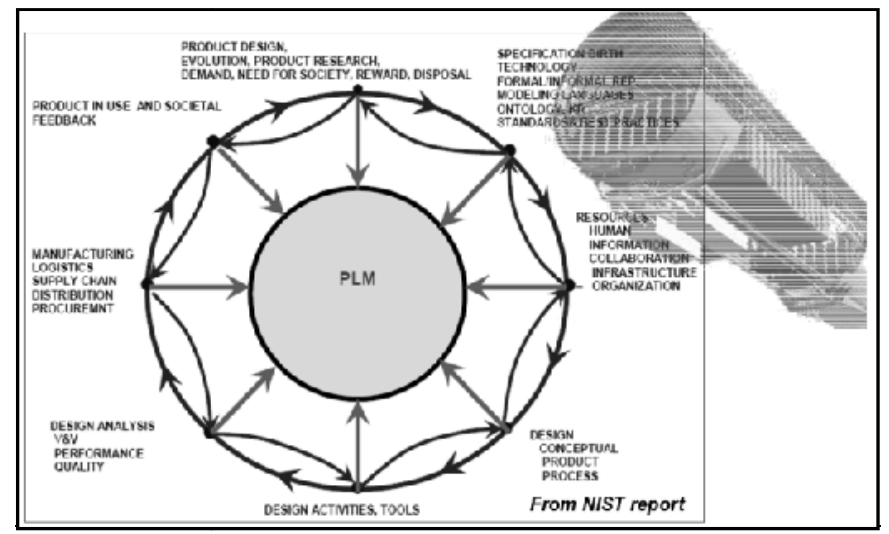

Figure 2.Fields covered for enveloping by an IDE

\section{Digital Mock Up Unit Under CONFiguration CONTROL}

The DMU is created in a CAD CAE CIM neutral, light weight format to enable diverse engineering groups to work and build the aircraft in virtual environment, - static, MBD and dynamic analysis, with Motions virtualized, test virtually and thus reduce reengineering, development time and cost. This Digital Mock Up of an aircraft created under configuration control using CAD neutral format replaces the old method of using costly Physical Mock Up [12]. The availability of the DMU especially in CAD neutral format of light nature enables, concurrent engineering based collaboration between various design groups of the aircraft regardless of their physical location or the type of CAD/CAE/CAM software they may be using clash/tolerance/interference/variance analysis along with assembly path planning is made possible in concurrent mode leading to parallel processing and optimal layouts. Further it aids the functions of design for manufacturing and design for Reliability Availability Maintainability (RAM) to be built in early in the design life. DMU makes all of the above possible. Parts and the product structure continually populate the DMU, evolving the e BOM. The lightweight format should be capable of seamless absorption of data from heterogeneous CAD/CAE systems [13].The lightweight CAD neutral DMU visualization process in PLM software allows visualizing a particular configuration or a product structure for all use processes under strict CC and change management control vital in aircraft design/manufacture/support procedures. It allows non-CAD users to gain access to the 3D model with an ease of use and without any training, for purposes of incorporation in documentation, promotional literature training [13].

According to EAI-649A standards, Configuration Management is defined as "A process that establishes and maintains consistency of a product's attributes with its requirements and product configuration information throughout the product's life cycle". This will apply to Product and Process. Applicability (called effectivity) with regard to tail number of the aircraft and state of the aircraft will be assigned. The engineering process- typically will start from the case-working engineer obtaining a PLM task with tentative product structure number assigned by PLM on the DMU as a unique e-BOM. The design sequence of modelling/checking for geometry produceability /maintainability/reliability /layout on DMU, mass, balance/ analysis will be tasked by PLM and carried out by concerned. Every change will be by a process. The system will feature a dynamic but controlled change management process under governance by a configuration control board at high level for major changes and a chief designer controlled local technical committee for minor changes. During the various stages in development, manufacture and use, there are bound to be changes and as such the configuration is controlled in several progressive AS -XXXX conditions as in Figure 3. The As-XXXX engineering state of the aircraft and the respective engineering activity is described in Table1. Any change to any Product or process 
International Journal of Advanced Information Technology (IJAIT) Vol. 3, No. 4, August 2013

documentation shall be scripted into the BOM only by the case working engineer in the design or methods group with the hierarchy of checking engineers having access and annotating facility only.

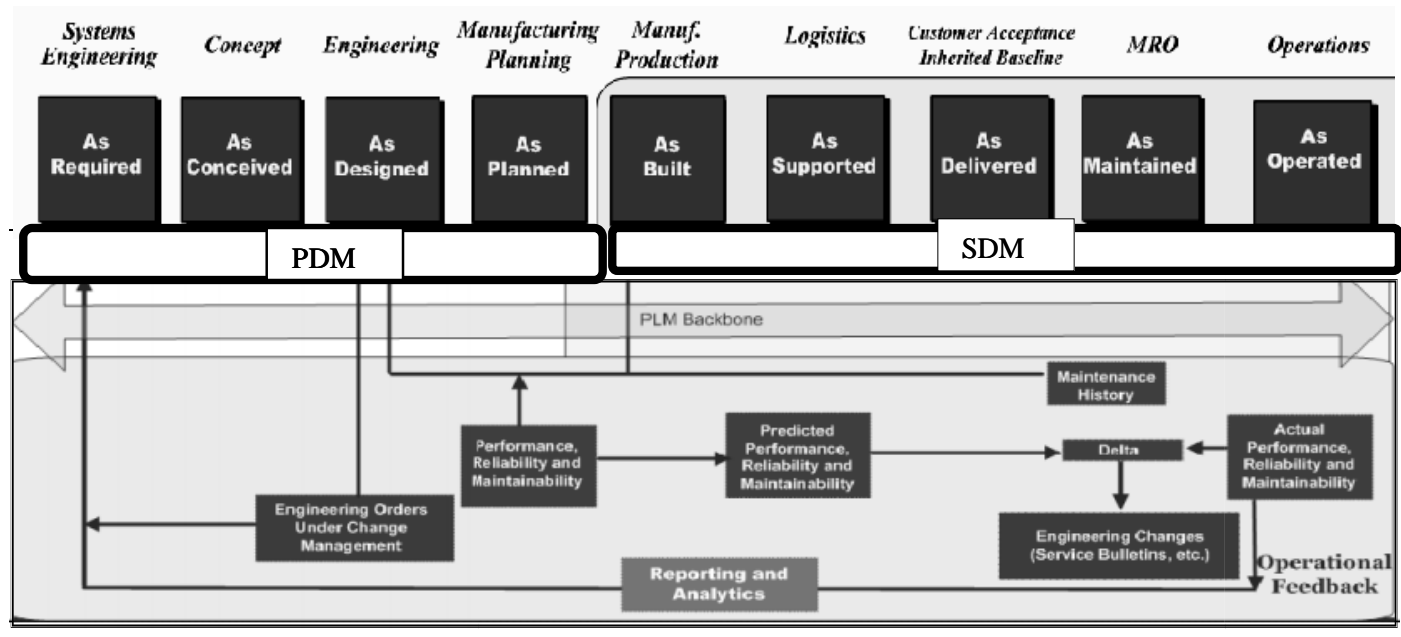

Figure 3. End to End engineering activity map of an aircraft PLM

Table1. Progression of the engineering state of the aircraft (Concept to Retirement)

\begin{tabular}{|c|c|}
\hline $\begin{array}{l}\text { Engineering state } \\
\text { of the Aircraft }\end{array}$ & Related Engineering Activities \\
\hline As Required & $\begin{array}{l}\text { Configuration identification on PLM; Performance; Operational requirement; } \\
\text { Produceability; Design to Cost/Life cycle Cost; Failure Effect Mode And } \\
\text { Criticality (FMCA); Maintenance; Sustainment; Supportability; } \\
\text { Availability/Reliability; Performance Based LOGISTICS (PBL) Metrics. }\end{array}$ \\
\hline As Conceived & $\begin{array}{c}\text { Configuration identification on PLM; Digital Mock-up (DMU); Aircraft } \\
\text { Specification; Finite Element Modeling; Preliminary System Design(Model Based } \\
\text { System Engineering(MBSE)); Preliminary Structure Design (Model Based } \\
\text { Design-MBD); }\end{array}$ \\
\hline As Designed & $\begin{array}{l}\text { Configuration identification on PLM;E-BOM; Detailed Design (geometry, } \\
\text { material, system, MBD,MBSE, elaboration) Design for Manufacture; Design for } \\
\text { Reliability and Maintenance; Digital process and Tool Concept. }\end{array}$ \\
\hline As Planned & $\begin{array}{c}\text { M-BOM; Digital Process Sheet; effort time \& estimate; Digital Detailed Tool } \\
\text { Design; Assembly Validation; Automation; Work Brealkdown Structure ;Co- } \\
\text { ordination with shop; Release of Process and Tool to production; First Article } \\
\text { Production; Sealing of process; Delivery to ERP for execution; Shop Brealkdown } \\
\text { Structure Closeout. }\end{array}$ \\
\hline As Built & $\begin{array}{l}\text { Configuration identification on PLM-TAII NUMBER; Work Instructions; } \\
\text { Manufacturing Execution System; Serialized Part5; Deviations; Shop Work Break } \\
\text { Down (SWBS) (Route Card) closeout; Functional Configuration Andit; Release } \\
\text { Flight Certificate; Flight Test Clearance; Release To Service. }\end{array}$ \\
\hline As Delivered & $\begin{array}{c}\text { Configuration identification on PLM-TAIL NUMBER; Product Structure; } \\
\text { Physical Configuration Audit; Serialized Part Numbers ; Baseline Configuration } \\
\text { Data; Asset Master Record Update. }\end{array}$ \\
\hline As Supported & $\begin{array}{c}\text { Configuration identification on PLM-TAII NUMMER; Operation Maintenance } \\
\text { Tasks; Skills; Hours; Parts; Tools; Materials;MII-Std-1388-2B; Integrated } \\
\text { Electronic Technical Manuals(IETM). }\end{array}$ \\
\hline As Operated & $\begin{array}{c}\text { Configuration identification on PLM-TAII NUMBER; Log Book; Environment; } \\
\text { Malfunction; Mean Time Between Failure(MTBF); Performance Problems; } \\
\text { Damage; Time/Life Limited; Failure Reporting Analysis And Corrective Action } \\
\text { System (FRACAS). }\end{array}$ \\
\hline As Maintained & $\begin{array}{l}\text { Configuration identification on PLM-TAIL NUMBER; Asset Master Records; } \\
\text { Plan Maintenance; Reserved Parts; Functional \& Configuration Fault Isolation; } \\
\text { Work Cards; Work Flow Execute. }\end{array}$ \\
\hline
\end{tabular}


International Journal of Advanced Information Technology (IJAIT) Vol. 3, No. 4, August 2013

\section{Model BASED DeSign (MBD)}

Conventionally, products were being designed in 2D drawings with $3^{\text {rd }}$ angle projection calling for very high visualization skills to understand and take up process design. The advent of 3D representation eased out the visualization part of the complexity. However, the attributes of the part or assembly such as dimensions, tolerances, special indicators of quality, material and surface conditions had to be furnished in separate documents enlarging the complexity of configuration control and traceability. Engineering drawings are subjected to a document lifecycle which includes data preservation, storage, destruction, security and transportation. They represent intellectual property, and are valued as evidence and as legal information [14]. The MBD file will contain all information, including those in the conventional 2D engineering drawings [15]. Using MBD files and DMU, the PLM software and infrastructure will govern under configuration control, a change process, the editing and manipulation of $\mathrm{CAD} / \mathrm{CAE} / \mathrm{CAM} / \mathrm{CIM}$ data created in any heterogeneous system, including revisioning, checkin/check-out, attributes, synchronization, automatically and bilaterally between native CAD and the Lightweight DMU. This is possible by use of Neutral CAD, Lightweight format for DMU. There is one or two PLM OEM light weight CAD Neutral software tools that support MBD, PLM-centric automation and lends itself to parallel and distributed processing [16]. The engineering process enable model based system engineering in system design with $100 \%$ model based design of objects and assemblies of the product.

Boeing B-777is reported to be one of the first in the aircraft industry to claim a $100 \%$ digital definition. Digital data were used to drive the manufacturing processes whenever possible. The entire aircraft assembly was simulated using digital techniques[17].With the advent of light weight CAD format in which the software can been stored and tweaked as and when required, a single file $\mathrm{MBD}$ is expected to provide all information governed by the light weight CAD neutral DMU and configuration control. This will enable collaboration and concurrency between various system design groups, avoid clash in layout and consequent reengineering, allow accurate mass and balance control and layout and contribute to innovation across the product lifecycle.

\section{Model BASED System Engineering}

Model Based system Engineering is a holistic, multidisciplinary and collaborative approach for designing and maintaining complex systems [18]. The "V" Diagram shown in the figure 4 covers all domains and approach that is followed [18].Data is generated once and handed down and used by customers along the data stream. Models form the pillars in model based engineering and are reused to drive all aspects of the product lifecycle [19]. When a model is initiated and developed from the initial stages of the project, it will be easier to carry out verification and validation of the safety critical software and its interfaces [20]. 


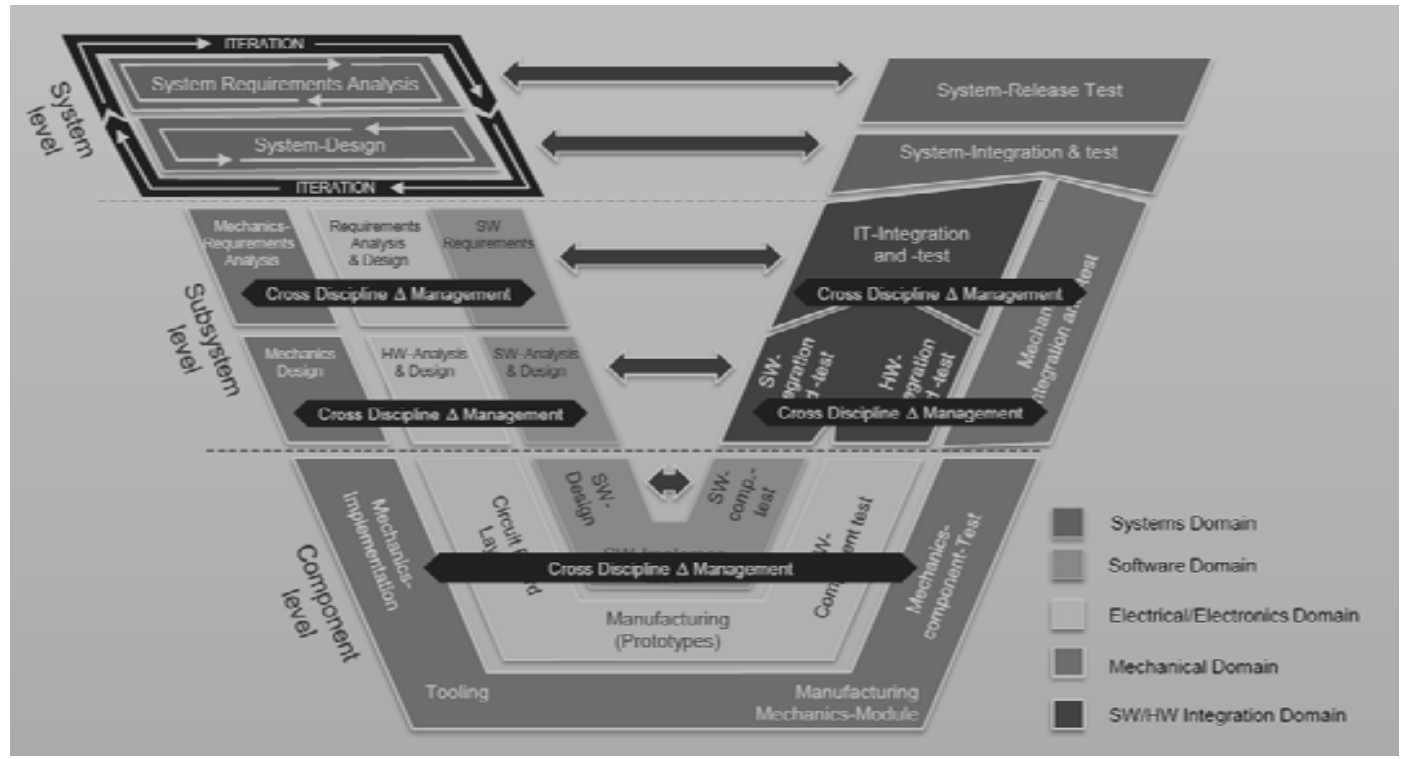

Figure 4. Model Based System Engineering Approach

\section{Digital Manufacturing Engineering In IDE/PLM}

With digital manufacturing software built into PLM Process designs will get refined for produceability, processes will get optimized early in design, and a single philosophy of high quality process tuneable to rated production can be decided early in the design cycle leading to economic production and low time to market.The processes of concurrency between design and methods including Design For Manufacturing and Assembly (DFMA) is described in in the V diagram as shown in the figure 5 .

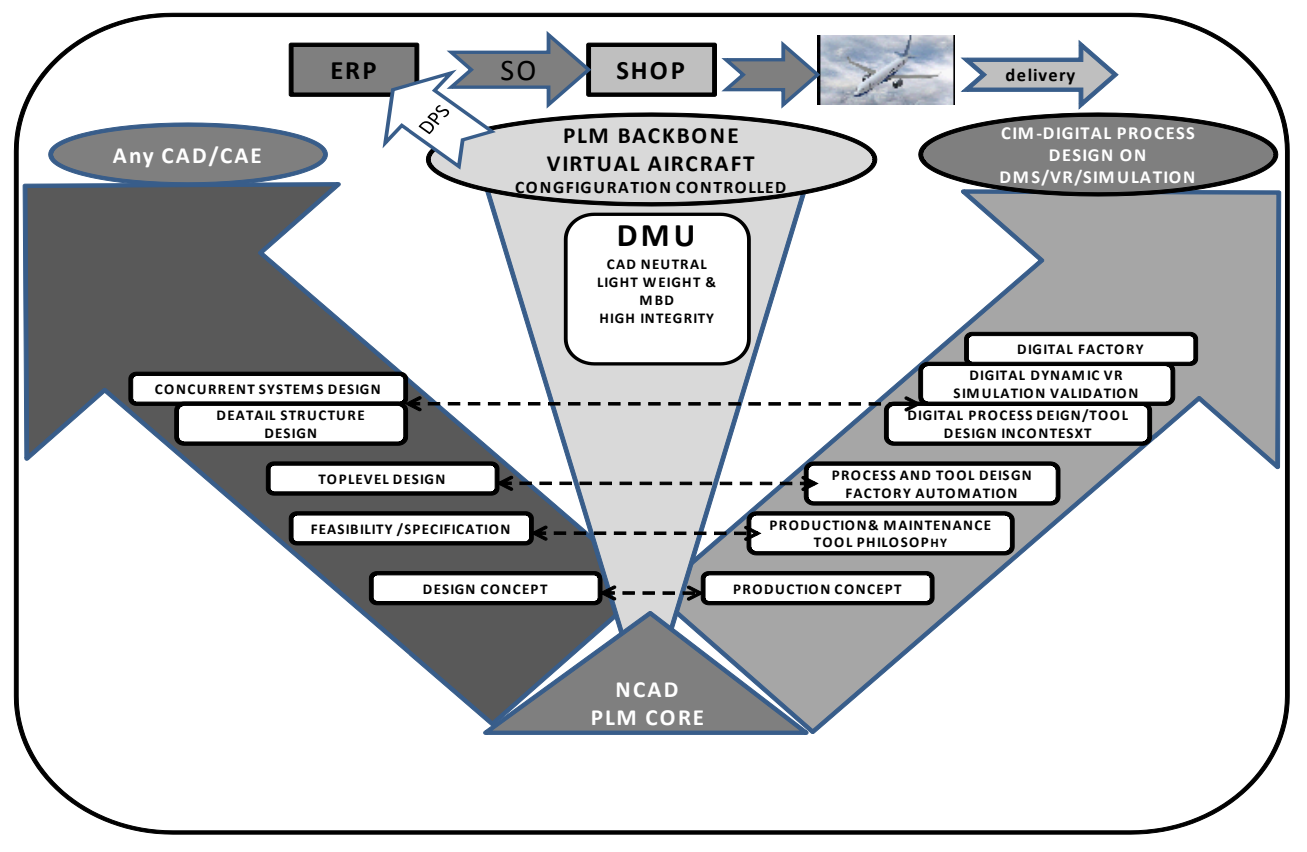

Figure 5.Concurrent product and process design engineering V diagram 


\section{Maintenance Repair OVERALl EngineERING In IDE/PLM}

The Aircraft has to be designed for Minimum maintenance with respect Scheduled maintenance, low failure rates, high wear life of parts, and maximized mean time of failures, and considerations in design have to run parallel with various stages of design and development. It requires coordinated work thought the life cycle of aircraft between Design/Manufacturing, Operating and Maintaining engineers. At present the maintenance Planning is commenced very late in the cycle probably starting only when the Prototype No 1 has taken to flights and gets into snags (that is about 3to 5 years from the Conceptualization of the aircraft The PLM approach with DMUs MBD and DMS ensures concurrent engineering. The concurrency is demonstrated in the V diagram as shown in the figure 6 .

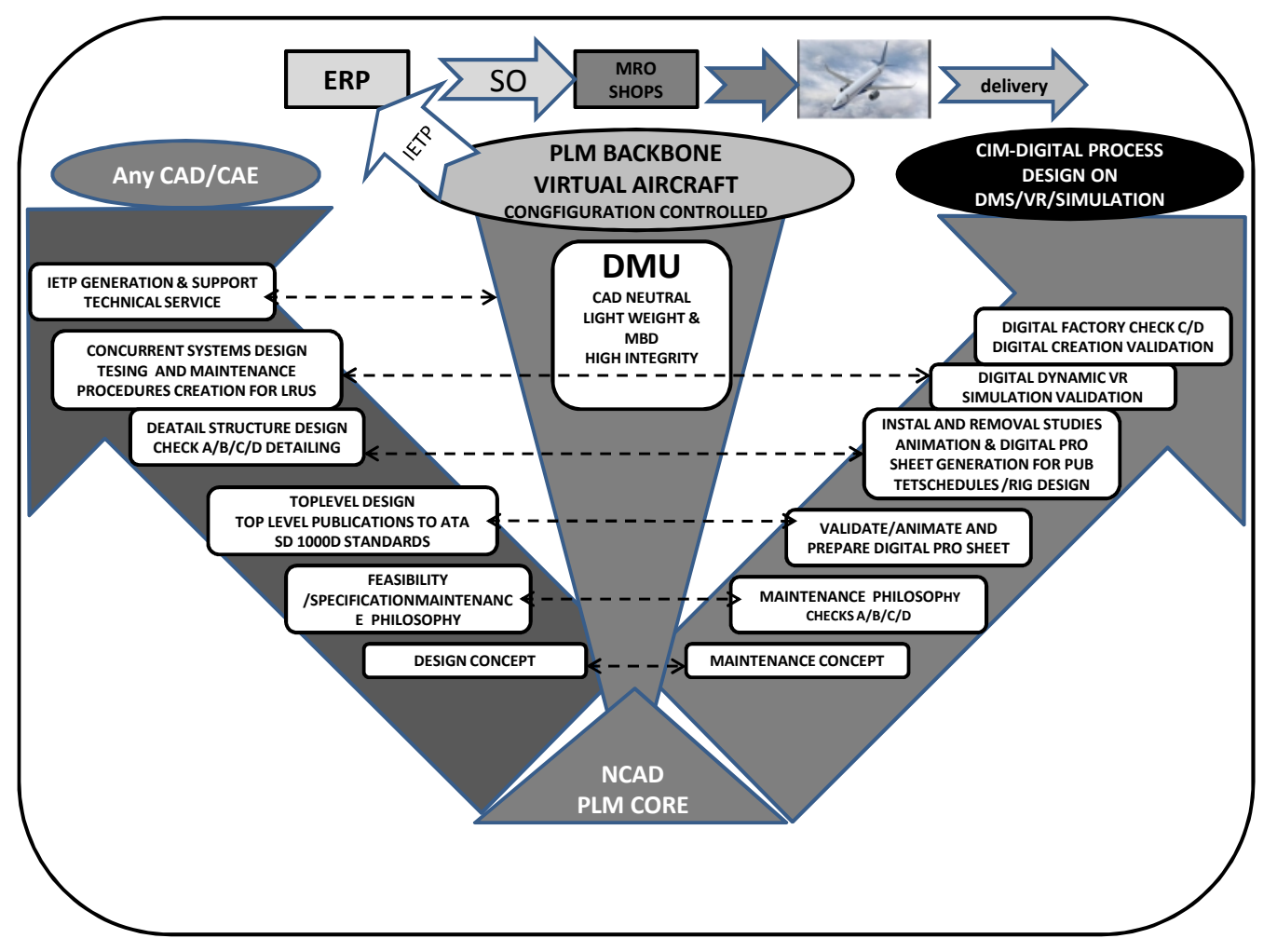

Figure 6. Maintenance Repair Overall (MRO) engineering process on PLM

\section{COLlaboRATIVE DESIGN AND DESIGN IN CONTEXT}

An exercise carried out to establish collaborative design and design in context processes under configuration control between structural designer, hydraulics designer and electrical designer of an aircraft under design using a neutral CAD lightweight DMU and several native CAD systems is presented. Configuration Control will commence on PLM with the ideation of the aircraft and creation of texts, graphics, etc of a Top Level Aircraft Requirement (TLAR) document. A PLM controlled unique numbering system will govern this document and all other child documents shall fall under the parent number, with a change process and number change as may be needed downstream of the concept right up to aircraft retirement. Typically, the PLM will govern the process for start of design as in the figure 7 below. 
International Journal of Advanced Information Technology (IJAIT) Vol. 3, No. 4, August 2013

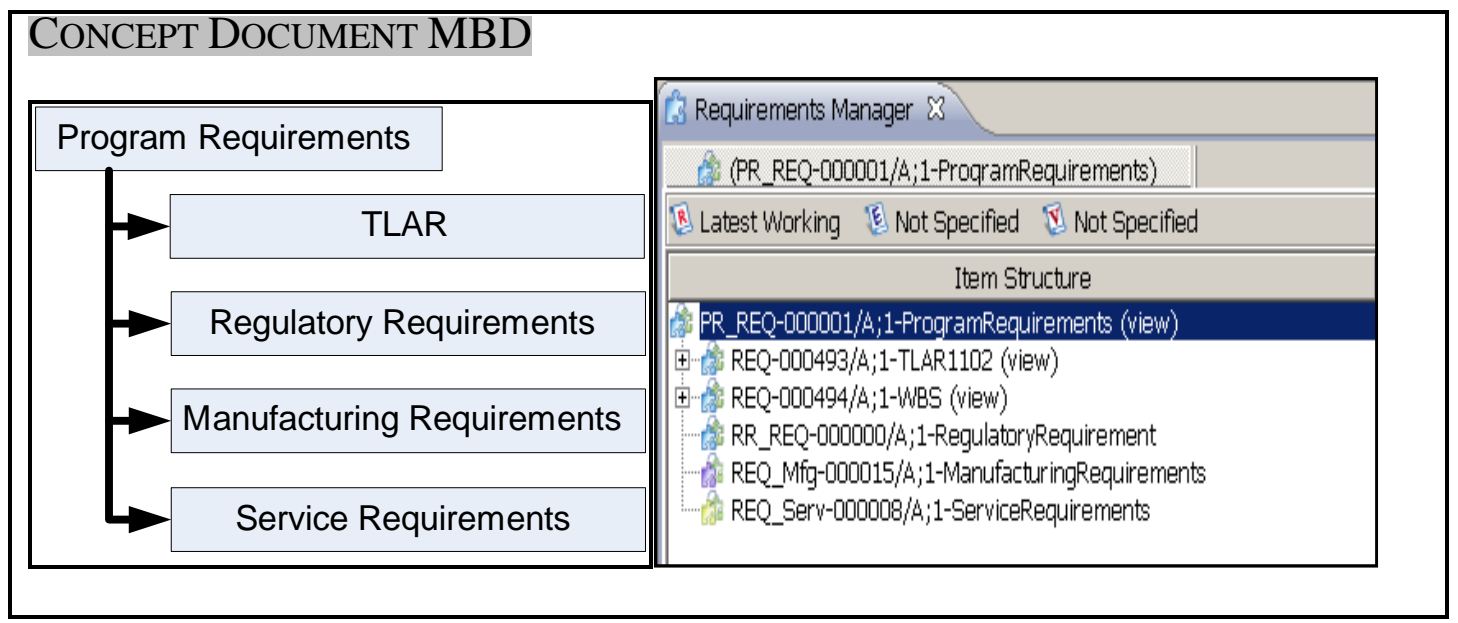

Figure 7. Requirement-BOM in PLM, with top level requirement, work break-down structure, Regulatory, Manufacturing and Service Requirements

Product Structure is defined by Chief Designer/Design quality cum Configuration Controller/ATA standards and Configuration standards such as EIA 636/849A from the TLAR as above and makes for TRACEABILITY to TLAR. The process for configuration controlled top level design schemes and top level DMU is shown in the figure 8 below.

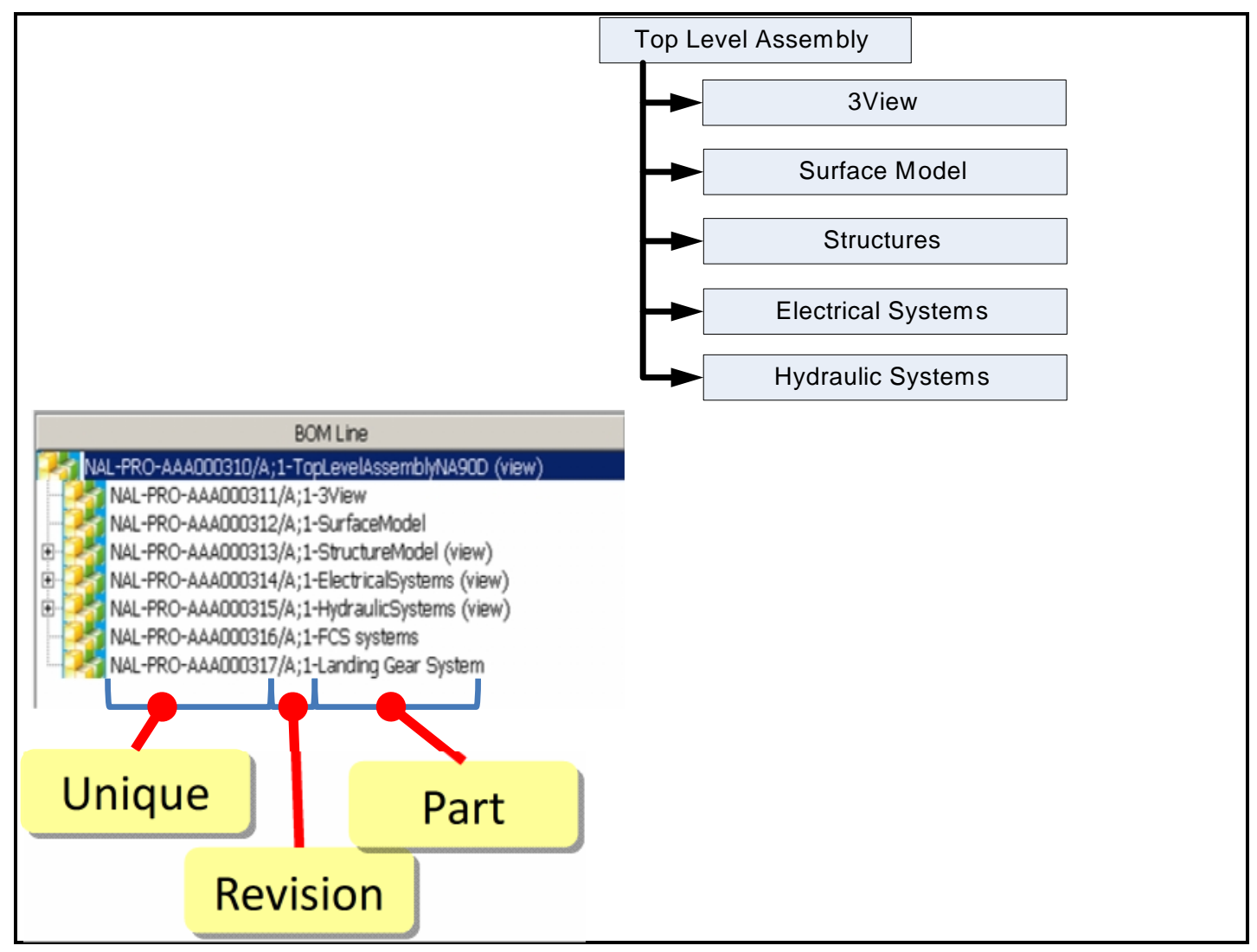

Figure 8. Product structure definitions with numbering system 
International Journal of Advanced Information Technology (IJAIT) Vol. 3, No. 4, August 2013

The derivation of collaboration capable DMU of Structure is shown in the figure 9.

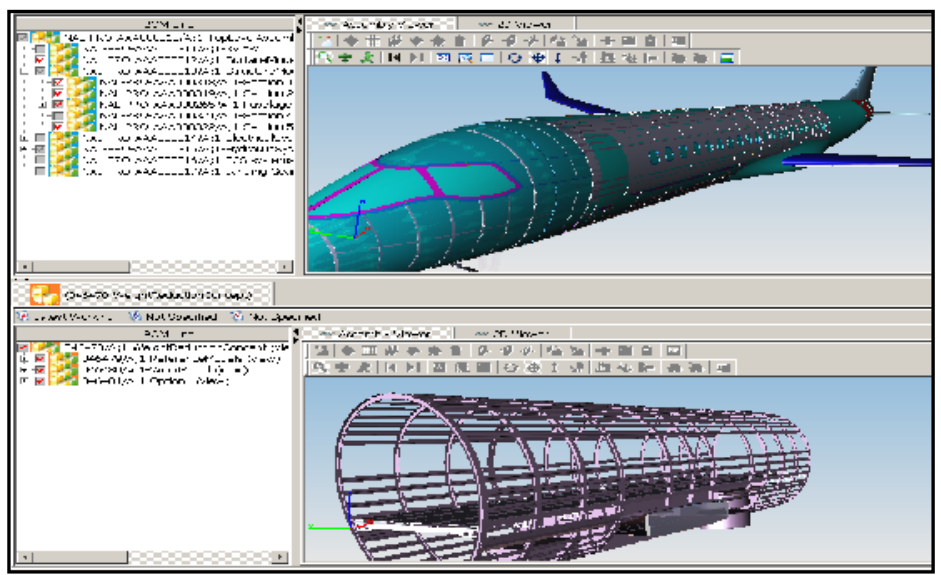

Figure 9. Derivation of Structure DMU in lightweight CAD neutral with e BOM

The Steps in Collaborated Design in Context of Electrical Installation DFM/DFMRO/release

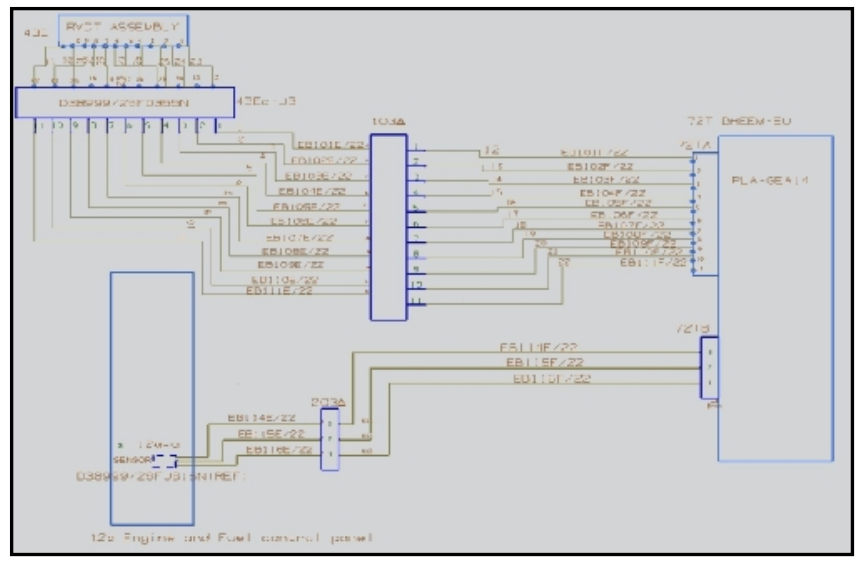

Figure 10. Wiring Schematic Logical data in any CAD

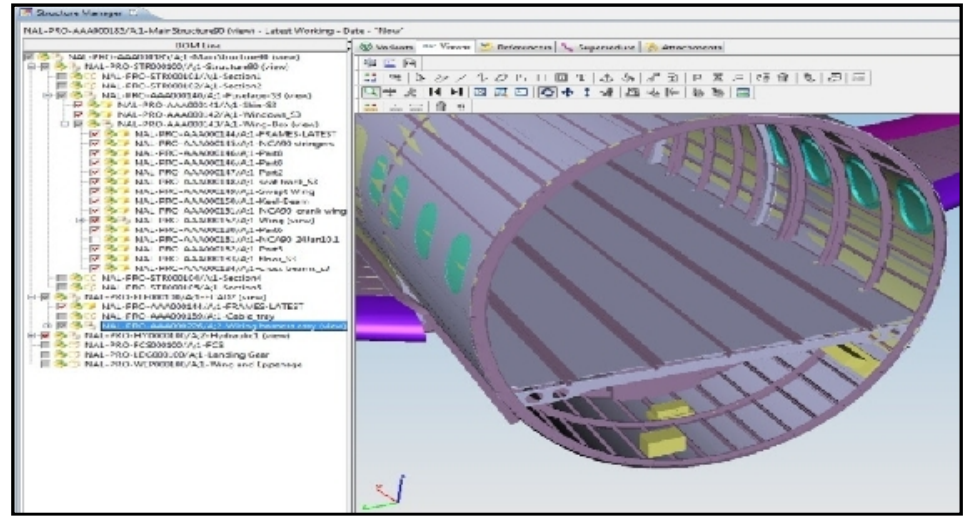

Figure11 DMU Devices are located in the DMU and synched with the schematics layout 
International Journal of Advanced Information Technology (IJAIT) Vol. 3, No. 4, August 2013

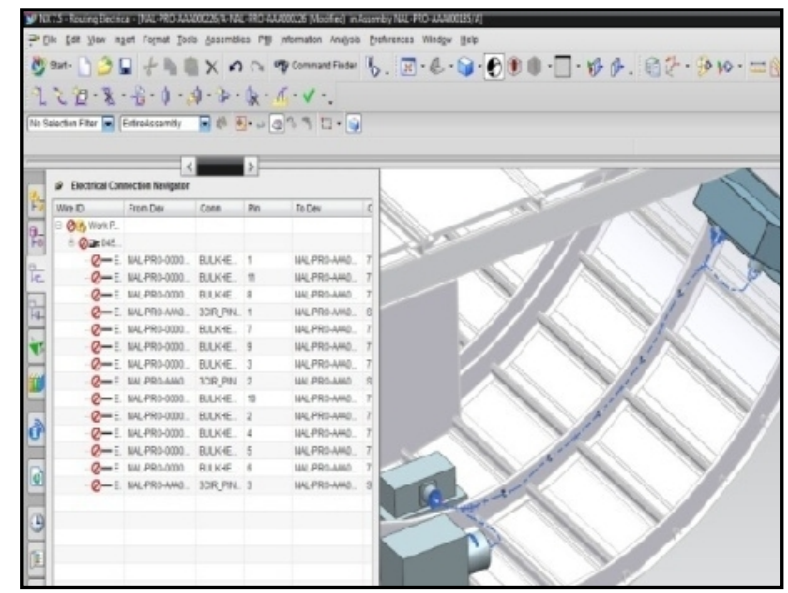

Figure12. Creation of Centre-line Routing

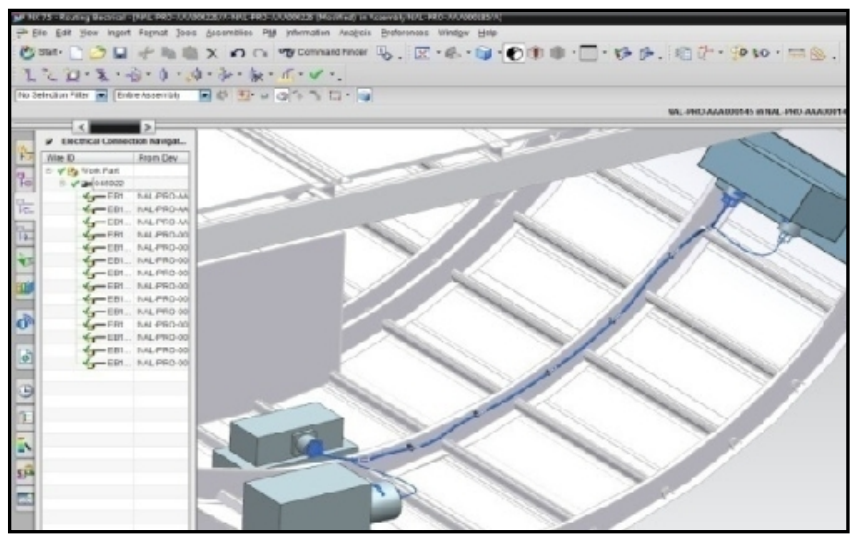

Figure13. Routing between connections along centre-line

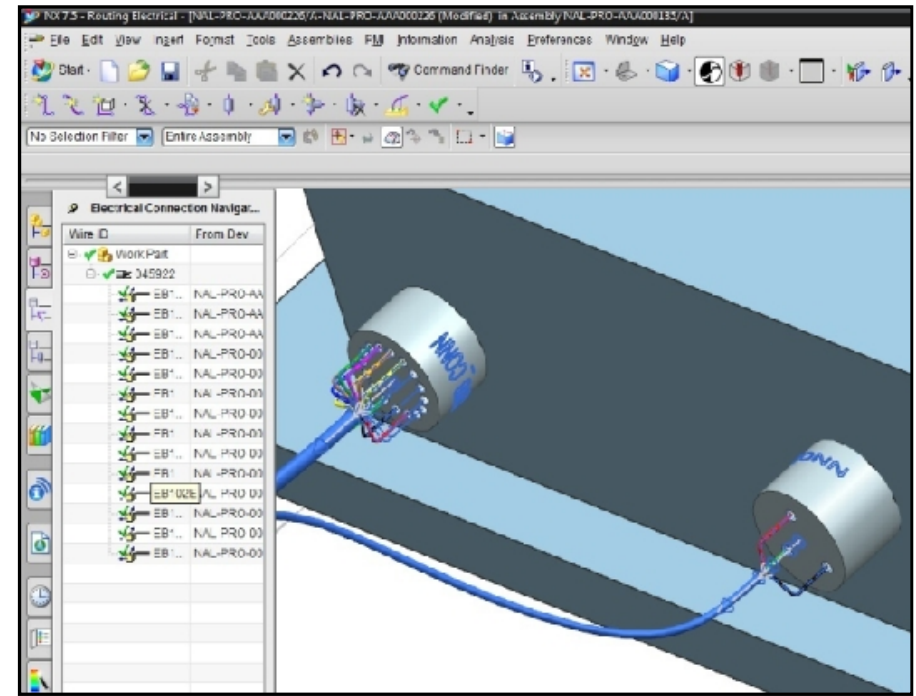

Figure14. Auto Routing at Pin Level 
International Journal of Advanced Information Technology (IJAIT) Vol. 3, No. 4, August 2013

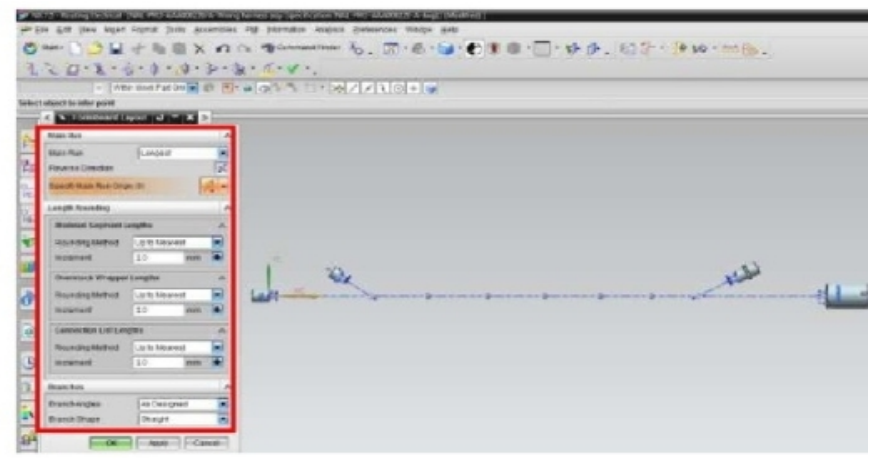

Figure15. Validation of Design rule (radius etc.)

The Collaborative engineering on light weight CAD neutral DMU in respect of a Hydraulic system is demonstrated below.
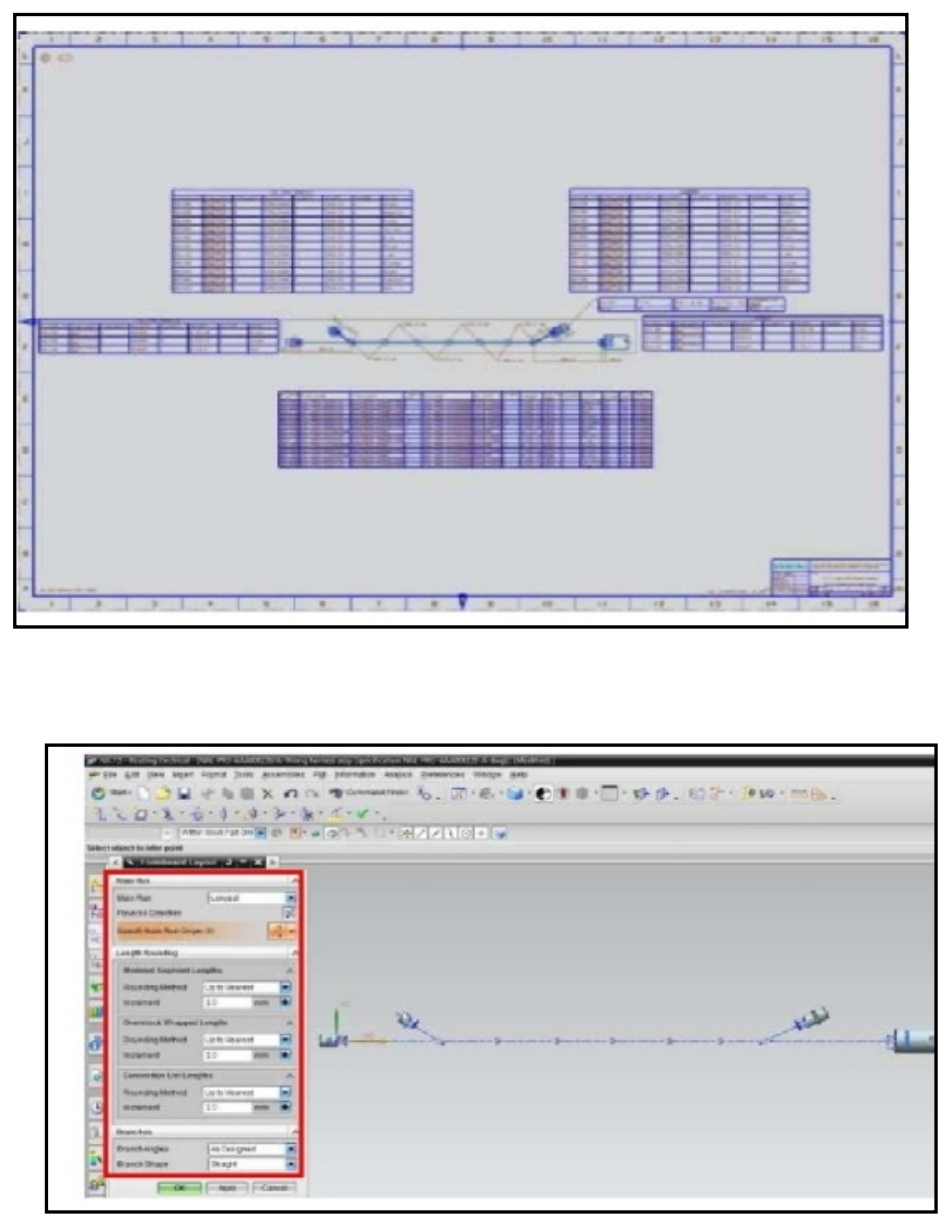

Figure 16. Screen shots of Automatic Form-board creation and different options for layout 
International Journal of Advanced Information Technology (IJAIT) Vol. 3, No. 4, August 2013

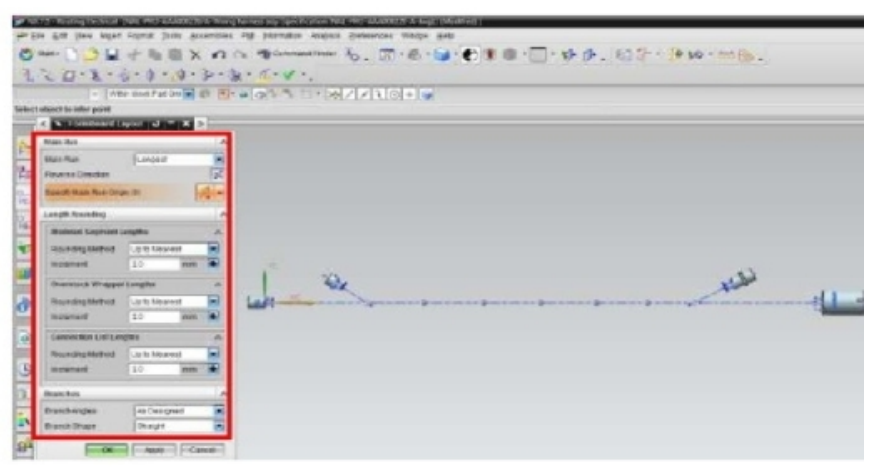

Figure 17.The Automatic Form-board drawing with connection list, pin list, length of wire and mass properties

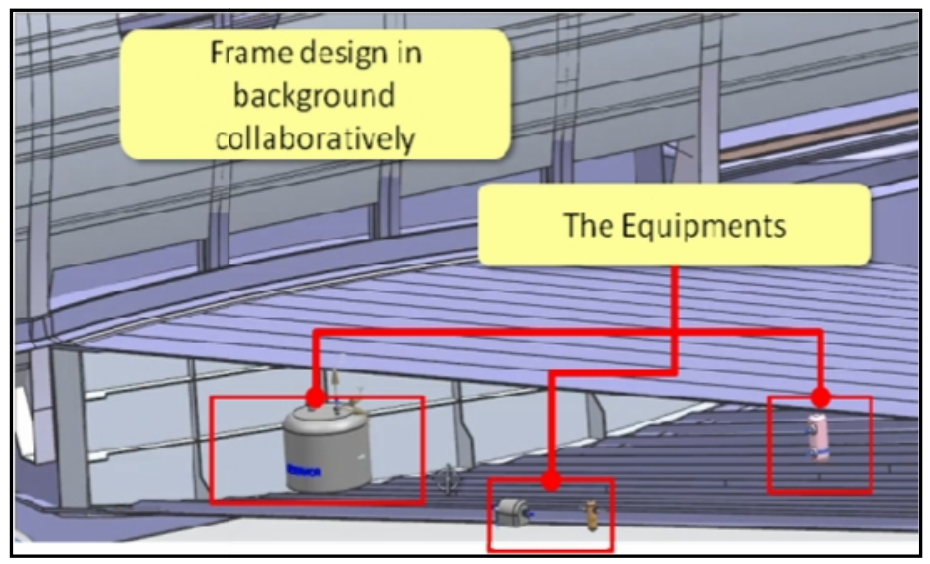

Figure 18. The equipments in context of assembly, in this case frame design (CAD Type 1) is being collaboratively performed by Structures

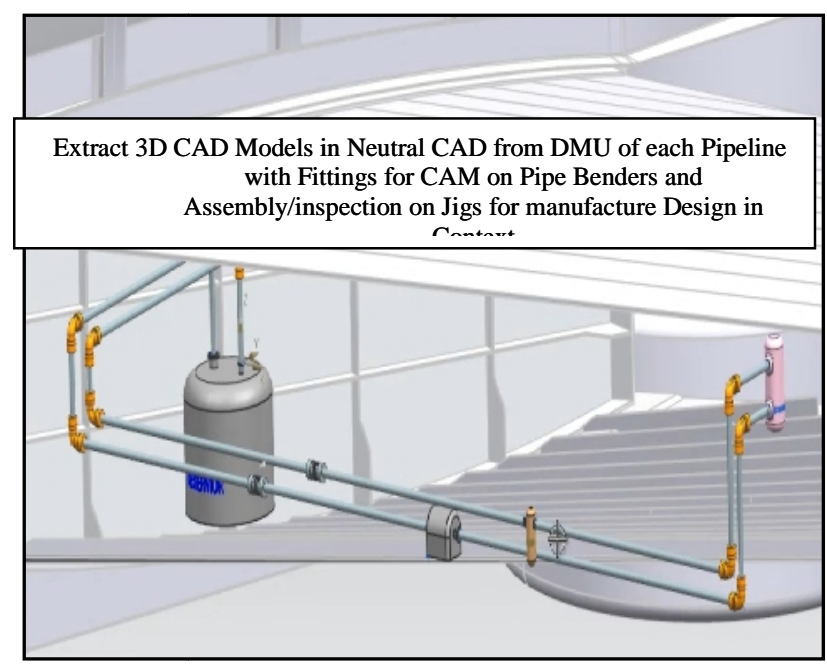

Figure 19. The Piping done interactively between equipments 
International Journal of Advanced Information Technology (IJAIT) Vol. 3, No. 4, August 2013

\section{CONCLUSIONS}

The engineering activities of an aircraft life cycle have transformed from vertically integrated organizations into highly distributed and collaborative mode involving subcontracting of various product and process design packages into tier 1, Tier 2 and tier 3 entities all over the worlds. These sources tend to operate with different CAD/CAE/CIM systems presenting heterogeneous software scenario. Concurrent engineering demands the creation of a virtual and 3D static, dynamic digital product platform and environment. Open standards and high interoperability, between software are needed. The use of MBD, MBSE and CAD neutral light weight DMU base engineering, all under configuration control in a PLM system will help achieve faster time to market and speedy continuous improvements in the life cycle. In the Indian context, most of the sub contracted engineering work requires Small and Medium Enterprise (SME) (Tier 3) level participants /partners by the aircraft prime. The SMEs or Universities, or Free lance specialists will not have the necessary techno economics to invest in high end infrastructure as they may not have enough orders to ensure maximum utilization and recover the investments. In such case, the CLOUD method and related infrastructure appears to be the right win-win investment decision. Collaboration through cloud computing has to be implemented. All R\& D organisations, manufacturing engineering groups, should be networked by appropriate IDE/PLM.

\section{ACKNOWLEDGEMENTS}

The authors would like to thank Mr. Shyam Chetty, Director, CSIR-NAL for conducting this study, Dr. Sathish Chandra, Project Director-NCAD and HOD STTD-NAL for guidance.

\section{REFERENCES}

[1] “IATA 2012 Annual Review”,http://www.iata.org/about/Documents/annual-review2012.pdf, pp1-60.

[2] Next Generation Continuous Capability Maturation - SAE", http://www/sae.org/events/dod/presentations/2012, pp 1-13 SAE.

[3] A. Whiteside, E. Shehab, 30-31 March 2009",Developing a Current Capability Design for Manufacture Framework in the Aerospace Industr", Proc. of the 19th CIRP Design ConferenceCompetitive Design, Cranfield University, ,pp223.

[4]S.G. Lee a,Y.-S. Maa, G.L. Thimm a, J. Verstraeten b, (2008) "Product lifecycle management in aviation maintenance,repair and overhaul", Computers in Industry 59 pp296-303.

[5] "Configuration Management in Aerospace and Defense: six key questions", 2012,http://www.accenture.com/SiteCollectionDocuments/PDF/ PP1-8

[6] Enrico Vezzetti ,"Product lifecycle data sharing and visualisation: Web-based approaches"(2009), Int J Adv Manuf Technol 41:613-630.

[7] D. Van Wijk, B. Eynard, N. Troussier, F. Belkadi, L. Roucoules, G. Ducellier, 30-31 March 2009"Integrated Design and PLM Applications in Aeronautics Product Development", Proc. of the 19th CIRP Design Conference - Competitive Design, Cranfield University, , pp128].

[8] Sergio Terzi,Marco Taisch,"Collaborative product development at a global scale: the role of PLM IT solutions",http://www.ami-communities.eu/pub/bscw.cgi /d494329/66_Terzi_and_Taisch_on_PLM.pdf

[9] Xun Xu, 28 (2012,"From cloud computing to cloud manufacturing" Robotics and ComputerIntegrated Manufacturing,) pp75-86

[10] S. Parekh, R. Roy and P. Baguley, 30-31 March 2009"Design and Manufacturing Uncertainties in Cost Estimating within the Bid Process:Results from an Industry Survey", Proc. of the 19th CIRP Design Conference-Competitive Design,Cranfield University, ,pp1788].

[11] Jean-Yves Delaunay, Thomas Drehmel,"European ebusiness standardisatio goverance "http://www.asdssg.org,accssed 22nd Aug. 2012.

[12] R. Stark, F.-L. Krause , C. Kind, U. Rothenburg, P. Müller, H. Stöckert, 30-31 March 2009" Competing in Engineering Design - the Role of Virtual Product Creation", Proc. of the 19th CIRP Design Conference-Competitive Design, Cranfield University, ,pp1 
International Journal of Advanced Information Technology (IJAIT) Vol. 3, No. 4, August 2013

[13] E. Shehab, M. Bouin-Portet, R. Hole, C. Fowler, 30-31 March 2009 "Enhancement of Digital Design Data Availability in the Aerospace Industry",.Proc. of the 19th CIRP Design Conference Competitive Design, Cranfield University, ,pp589.

[14] R.Pedauque,"Document:Form, Sign and Medium, as Reformulated for Electronic Documents",2003, http://archivesic.ccsd.cnrs.fr/docs/00/06/22/28/PDF/sic_00000594.pdf

[15] Virgilio Quintana a, Louis Rivest a, Robert Pellerin b, Fre'de' rick Venne a, Fawzi Kheddouci a, (2010) "Will Model-based Definition replace engineering drawings throughout the product lifecycle? A global perspective from aerospace industry". Computers in Industry 6,1pp 497-508

[16] Jonathan G. Lund, Nathanie L. Fife and C. Gregory Jensen3, 2005, "PLM-Based Parametrics for Design Automation and Optimization", Computer-Aided Design \& Applications, Vol. 2, Nos. 1-4, pp $37-45$

[17] K.J. Sharma, B. Bowonder, 6 (3-4) (2004),"The making of Boeing 777: a case study in concurrent engineering", International Journal of Manufacturing Technology and Management, pp254-264.

[18] Andrew Wertkin, 92011) "Driving Innovation and quality through Systems Engineering",CIMdata,pp1-20.

[19] Joshua Lubell,Kenway Chen,John Horst,Simon Frechette,Paul Huang,August 2012, "Model Based Enterprise /Technical Data Package,Summit Report", NIST Technical Note 1753,pp1-111

[20] Sara C. Spangelo,James Cutler,Louise Anderson,Elyse Fosse,Leo Cheng,Rose Yntema,Manas Bajaj,Chris Delp,Bjorn Cole,Grant Soremekum,David Kaslow(2013) "Model Based Systems Engineering (MBSE) Applied toRadio Aurora Explorer (RAX) CubeSat MissionOperational Scenarios" IEEEAC Paper \#2170, Version 1, pp1-18

\section{AUTHORS}

Short Biography

Bhanumathi K. S. received her M.S. Degree in Software Systems from BITS, Pilani, and M.Sc. M.Phil., Degrees in Mathematics from Bangalore University. She has worked as a Scientist at Defence Research and Development Organisation (DRDO) for 28 years, during which she has been actively involved in the Design and Development of Avionics and Weapon systems software for Light Combat Aircraft(LCA) project, Mission Computer software for Cockpit Environment Facility (CEF) of LCA project, Lead Angle Computation of Air to Air gun, Vendor Projects of ADA, Product Life Cycle Management solution for LCA project across Aeronautical Development

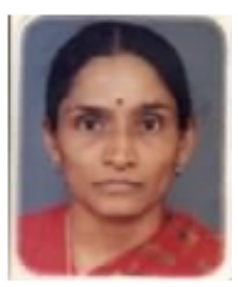
Agency (ADA), Aircraft Research and Development Centre (ARDC) of Hindustan Aerospace Limited and Limited Series Production (LSP) at Aircraft Division of Hindustan Aerospace Limited. She has shown the way and been a team leader in many of these projects. Currently she is working for National Civil Aircraft Development (NCAD) Project under Council of Scientific \& Industrial Research (CSIR)-National Aerospace Laboratories (NAL). Bhanumathi's interest are in the realm of Model Based Design (MBD),Model Based Systems Engineering (MBSE) and the use of open standards to establish global collaboration using light weight neutral CAD,CAM,CAE for end to end product and systems lifecycle management (PLM/SLM) system in the aerospace industry.

B Haridas, majored in the Mechanical Engineering from Mysore University and holds a masters in Manufacturing Engineering from I. I. Sc. Served department of atomic energy in the areas of reactor equipment Design, Manufacture, as a manufacture engineer including sounding rockets. Moved to aeronautical industry and served Hindustan Aeronautics Ltd. Finished at the position of director corporate Planning. After retirement continued to serve Light Combat Aircraft for its productionisation and followed up similar activity in manufacturing. design assistance to NCAD, during all these he has involved in implementation of ERP and PLM solutions

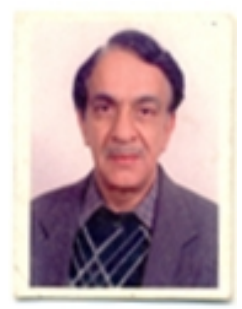

